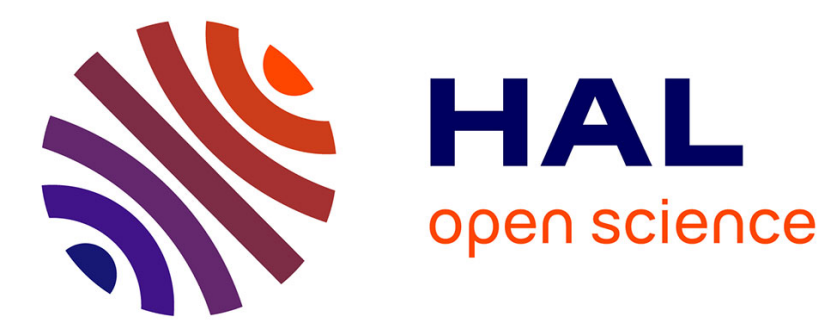

\title{
Evaluation of kernel-driven BRDF models for the normalization of Alpilles/ReSeDA POLDER data
}

Marie Weiss, Frédéric Jacob, Frédéric Baret, Agnès Pragnère, Claude

Bruchou, Marc Leroy, Olivier Hautecœur, Laurent Prévot, Nadine Bruguier

\section{- To cite this version:}

Marie Weiss, Frédéric Jacob, Frédéric Baret, Agnès Pragnère, Claude Bruchou, et al.. Evaluation of kernel-driven BRDF models for the normalization of Alpilles/ReSeDA POLDER data. Agronomie, 2002, 22, pp.531 - 536. 10.1051/agro:2002037 . hal-03541160

\author{
HAL Id: hal-03541160 \\ https://hal.science/hal-03541160
}

Submitted on 24 Jan 2022

HAL is a multi-disciplinary open access archive for the deposit and dissemination of scientific research documents, whether they are published or not. The documents may come from teaching and research institutions in France or abroad, or from public or private research centers.
L'archive ouverte pluridisciplinaire HAL, est destinée au dépôt et à la diffusion de documents scientifiques de niveau recherche, publiés ou non, émanant des établissements d'enseignement et de recherche français ou étrangers, des laboratoires publics ou privés. 


\title{
Evaluation of kernel-driven BRDF models for the normalization of Alpilles/ReSeDA POLDER data
}

\author{
Marie WeISS ${ }^{a *}$, Frédéric JACOB ${ }^{\mathrm{b}}$, Frédéric BARET ${ }^{\mathrm{c}}$, Agnès PRAGNÈrE ${ }^{\mathrm{c}}$, Claude BRUCHOU ${ }^{\mathrm{c}}$, \\ Marc LEROY ${ }^{\mathrm{d}}$, Olivier HAUTECEUR ${ }^{\mathrm{a}}$, Laurent PRÉVOT ${ }^{\mathrm{c}}$, Nadine BRUGUIER ${ }^{\mathrm{c}}$ \\ ${ }^{a}$ NOVELTIS, parc technologique du canal, 2 avenue de l'Europe, 31520 Ramonville Saint-Agne, France \\ ${ }^{\mathrm{b}}$ USDA/ARS Hydrology and Remote Sensing Laboratory, Beltsville, MD, USA \\ ${ }^{c}$ INRA, Domaine Saint-Paul, Site Agroparc, 84914 Avignon Cedex 9, France \\ ${ }^{\mathrm{d}}$ CESBIO, 18 avenue E. Belin, BPI 2801, 31401 Toulouse Cedex 4, France
}

(Received 25 September 2001; accepted 11 December 2001)

\begin{abstract}
A Bidirectional Reflectance Distribution Function (BRDF) catalog of different crops (mainly wheat, alfalfa, sunflower and maize) was acquired during the whole crop cycles in 1997 (ReSeDA experiment). This was achieved using the airborne POLDER sensor. Data were thus available in four wave bands ( 10 or $20 \mathrm{~nm}$ width) centered on $443 \mathrm{~nm}, 550 \mathrm{~nm}, 670 \mathrm{~nm}$ and $865 \mathrm{~nm}$. The aim of this study is to compare the ability of BRDF models to accurately fit and extrapolate POLDER BRDF data for a normalization process. We considered linear or semi-linear BRDF models that describe the BRDF with few parameters (3 to 6) and allow fast inversion procedures. We first developed two linear BRDF models (FLIK, Flexible Linear Kernels and GEN, generic model), and compared them to existing ones in the literature. The results are discussed as a function of the number of directional data and their distribution in the hemisphere for each acquisition date.
\end{abstract}

remote sensing / linear BRDF models / inversion

Résumé - Évaluation de modèles linéaires à noyaux de BRDF pour la normalisation des données aéroportées POLDER de la campagne Alpilles/ReSeDA. Un catalogue de données de réflectance bidirectionnelle (BRDF), acquis avec le capteur aéroporté POLDER, correspondant à plusieurs types de cultures (principalement du blé, de la luzerne, du tournesol et du maïs) a été acquis lors de la campagne Alpilles/ReSeDA, tout au long des cycles de cultures en 1997. Des données de réflectance bidirectionnelle sont donc disponibles dans quatre bandes, larges de 10 à $20 \mathrm{~nm}$ et centrées sur $443 \mathrm{~nm}, 550 \mathrm{~nm}, 670 \mathrm{~nm}, 865 \mathrm{~nm}$. Le but de cette étude est de comparer l'aptitude des modèles linéaires de BRDF à estimer et extrapoler précisément les données de réflectance POLDER, dans le cadre d'un processus de normalisation. Nous considérons des modèles linéaires ou semi-linéaires qui permettent de décrire la BRDF avec peu de paramètres (entre 3 et 6 ) ainsi que des procédures d'inversion très rapides. Nous présentons d'abord le développement de deux modèles: FLIK, Flexible Linear Kernels, et GEN un modèle générique, puis les comparons avec des modèles existants dans la littérature. Pour chaque date d'acquisition, les résultats sont discutés en fonction du nombre de données bidirectionnelles diponibles pour l'inversion, ainsi que de leur répartition dans l'hémisphère.

télédétection / modèles de BRDF linéaires / inversion

\section{INTRODUCTION}

Remote sensing in the optical domain is one of the main tools that quantify the state variables and the processes occurring at the Earth's surface. Seasonal observations are indeed required to evaluate canopy temporal changes. Further, a global coverage is also required in many cases to map the characteristics of the canopy. For example, they are necessary for global circulation models to evaluate the energy and mass fluxes on a global scale. Large-scale sensors such as NOAA/AVHRR, POLDER, VEGETATION, MODIS, MISR, MERIS..., are particularly well suited to addressing this issue. The interpretation of the temporal profile recorded over a given area and derived from these sensors requires that

Communicated by Andres Kuusk (Toravere, Estonia)

* Correspondence and reprints

weiss@avignon.inra.fr 
the atmospheric effects and anisotropy of the target have to be taken into account, or at least corrected. This leads to the development of the so-called compositing algorithms that provide a radiometric signal for which the canopy information is enhanced and the atmospheric and bi-directional effects are minimized. These algorithms consist of normalizing the reflectance data. This could allow one to ensure the comparison of remote sensing data from one sensor to another, assuming that spectral considerations also have to be taken into account [7]. Compositing algorithms are divided into two groups:

- Maximum Composite Value (MVC), [3, 5, 17]: it is a simple method based on the use of vegetation indices (VIs). VIs are combinations of reflectances in different bands, and particularly in the red and near infrared domains. These combinations enhance the effect of the vegetation as compared with the soil. The MVC technique consists of selecting the maximum VI value over a determined period (usually a decade) for a given pixel to avoid the effects of atmosphere and clouds. Compositing algorithms do not account for changes in VIs as a result of sensor degradation, solar zenith angle, and/or soil background collected at near-nadir view angles under cloud-free, clear atmosphere conditions [10]. Therefore, although MVC techniques are very fast, they are not a good way to normalize data from bi-directional effects.

- BRDF linear models (or kernel-driven models) [13, 21, 23]: this technique consists of inverting a simple BRDF model on a selection of bidirectional reflectance data. Once the model parameters are retrieved, the model can be run in the forward direction to estimate the reflectance in given directions, or the spectral albedo. As compared with VIs, BRDF models provide a normalized variable that corresponds to the same viewing and solar conditions. This technique is also fast since it resumes with the computation of a pseudo inverse matrix.

This study is dedicated to the comparison of ten BRDF models. The comparison was performed in terms of the model's ability to accurately fit Top Of Canopy (TOC) bidirectional reflectance data. The extrapolation capacities of the model were also investigated when inverted on a selected amount of directions. This was performed using POLDER data of the Alpilles/ReSeDA campaign. Two linear models were also developed.

\section{MATERIALS AND METHODS}

\subsection{The Alpilles/ReSeDA BRDF data set}

Airborne BRDF data were acquired during the whole Alpilles/ReSeDA campaign [1], for 16 acquisition dates distributed throughout the year. The acquisition was performed for two hours at the solar noon. Images were corrected from instrumental, geometrical and atmospheric effects by the CESBIO [12]. They were delivered in a Lambert II projection at a $20 \mathrm{~m}$ spatial resolution. Five flight lines were performed

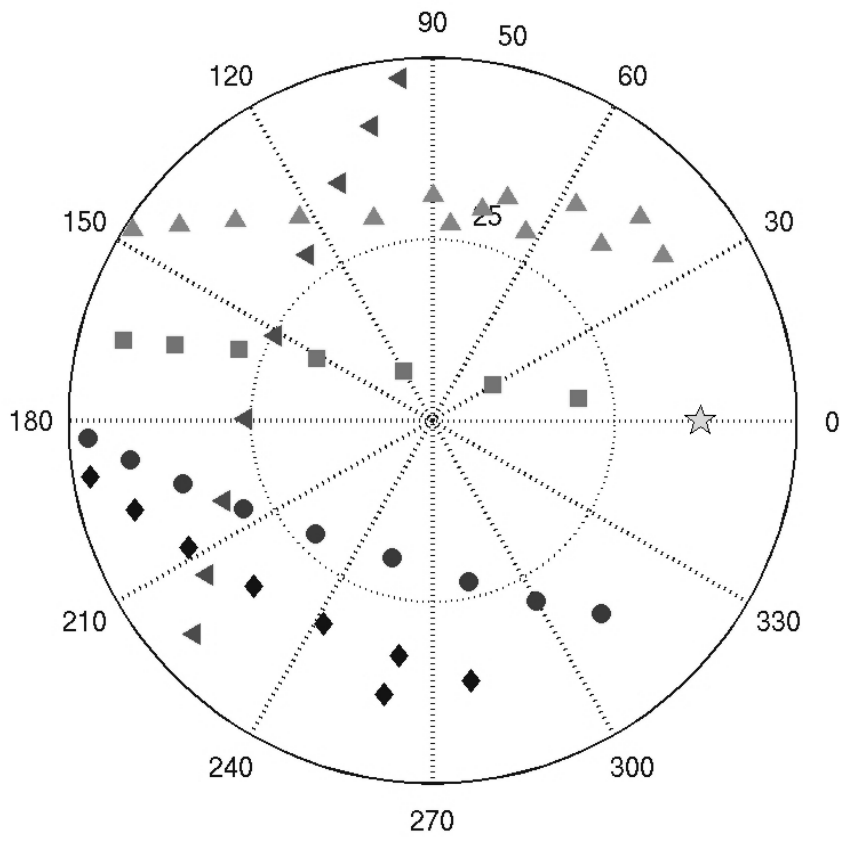

Figure 1. Polar representation of POLDER BRDF sampling. Sun position is located with a $\downarrow$, the relative azimuth angle is represented by the spokes, circles correspond to zenith angles. Flight lines are represented with different symbols.

during the acquisition of the BRDF. In this study, we only focused on the 37 agricultural fields that were monitored by ground measurements. Each field was located on the image using a precise map and GIS, in the same projection as POLDER images. Edges were eliminated to avoid mixed pixels. For each field and image, the geometrical correction was refined using correlation between POLDER NDVI and SPOT NDVI, since SPOT images were more accurately geometrically corrected. The extracted field BRDF corresponds to the average reflectance value over the inside pixels of the sampled crop. An example of the sampling for one crop at one date is given in Figure 1. There is one flight line close to the principal plane and another one close to the perpendicular plane. The three other lines are further from the principal plane. Using this sampling, it is possible to test kernel-driven models on the accuracy of the fitting, as well as on their ability to extrapolate reflectance in flight lines other than the one used for the inversion.

\subsection{Kernel-driven BRDF models}

Kernel-driven models are generally empirical or semi-empirical and describe the directional variation of the reflectance with few parameters (3 to 6 ). The main advantage is that the inversion process is reduced to a pseudo-matrix inversion. This allows operational processing of remote sensing images. For the numerous models existing in the literature (see the review of [21]), bidirectional reflectance $(\rho)$ is expressed as a linear combination of kernels $(K)$ that 
are functions of the view $\left(\theta_{\mathrm{v}}\right)$ and solar $\left(\theta_{\mathrm{s}}\right)$ zenith angles and the relative azimuth angle $(\varphi)$ between the sun and the sensor $[15,22,23]$

$$
\rho\left(\theta_{\mathrm{v}}, \theta_{\mathrm{s}}, \varphi, \lambda\right)=\sum_{\mathrm{i}=1}^{\mathrm{n}} \alpha_{\mathrm{i}}(\lambda) \mathrm{K}_{\mathrm{i}}\left(\theta_{\mathrm{v}}, \theta_{\mathrm{s}}, \varphi\right) .
$$

The coefficients $\alpha_{i}$ depend on the spectral band $\lambda$ and on the type of canopy observed by the sensor; $n$ is the number of model parameters. When considering a set of bidirectional reflectance measurements, the model can be inverted using pseudo matrix inversion:

$$
[\rho]=[\mathrm{K}][\alpha] \Rightarrow[\alpha]=[\mathrm{K}]^{-1}[\rho] \text {. }
$$

In this paper, we consider ten BRDF models:

- A very simple model that consists of taking the nadir reflectance $\rho_{0}$ as an estimate of any bidirectional reflectance.

- Models from the literature: MRPV [6], Walthall (non-reciprocal form) [20], Roujean [16], and Li-dense/ Ross-thick (Li-Ross) [21].

- Two models that we developed: GEN (Sect. 2.2.1) and FLIK (Sect. 2.2.2). The FLIK model can be derived in 4 models differing by their number of parameters.

Table I presents a comparison of the model's properties. The number of model parameters is an important feature since, depending on cloud occurrence and the latitude of observation, the inversion process may be performed on very few bidirectional reflectance data. Considering that for large swath sensors, reflectances are acquired at a quasi-constant zenith solar angle for a given pixel, the reciprocity property is interesting to extrapolate reflectance for other solar positions. This could allow, on one hand, the normalization of the data acquired by the sensor for the same view and solar position, and on the other hand, the estimation of the albedo integrated value during the day. Some models also take into account the hot spot feature, that is characterized by a higher reflectance level in the principal plane with a peak in the solar direction [11]. This may be useful if the sensor is able to sample reflectance in the principal plane, like the POLDER instrument.

\subsubsection{The GENeric model (GEN)}

The generic model is based on the idea that there is a "generic" shape of the BRDF for any kind of surface. To accurately fit the BRDF of a given area, the generic shape can be

Table I. Comparison of BRDF model properties.

\begin{tabular}{lcccl}
\hline Model & Nb of parameters & Reciprocal & Hot spot & Approach \\
\hline Nadir & 1 & Yes & No & Empirical \\
Walthall & 3 & No & No & Empirical \\
MRPV & 3 & Yes & Yes & Semi-empirical \\
Roujean & 3 & Yes & Yes & Semi-empirical \\
Li-Ross & 3 & Yes & Yes & Semi-empirical \\
GEN & 2 & Yes & Yes & Semi-empirical \\
FLIK3 & 3 & Yes & Yes & Semi-empirical \\
FLIK4 & 4 & Yes & Yes & Semi-empirical \\
FLIK5 & 5 & Yes & Yes & Semi-empirical \\
FLIK6 & 6 & Yes & Yes & Semi-empirical \\
\hline
\end{tabular}

shifted by multiplying it by a factor and/or adding an offset. The generic shape was first determined by using the database provided by [2]. It corresponds to various canopy BRDF (about 350) acquired by the POLDER instrument from November 1996 to June 1997 . The MRPV model was inverted to get the 3 parameters $\alpha_{i}(\lambda)$ for each pixel and acquisition date in the four POLDER bands. The MRPV was chosen since it is one of the most accurate models $[22,23]$. The root mean square error between the measured BRDF and the one estimated after MRPV inversion is less than 0.05 for the whole database. The "generic" shape is then obtained by averaging the 3 MRPV parameters over all the situations described in the database:

$$
\rho_{\mathrm{GEN}}\left(\theta_{\mathrm{v}}, \theta_{\mathrm{s}}, \varphi, \lambda\right)=\sum_{\mathrm{i}=1}^{3} \bar{\alpha}_{\mathrm{i}}(\lambda) \mathrm{K}_{\mathrm{i}}^{\mathrm{MRPV}}\left(\theta_{\mathrm{v}}, \theta_{\mathrm{s}}, \varphi\right)
$$

where $\bar{\alpha}_{\mathrm{i}}(\lambda)$ are the 3 averaged MRPV parameters (over all the pixel/date situations), $K_{i}^{\text {MRPV }}$ are MRPV kernels and $\rho_{\text {GEN }}$ is the "generic" BRDF. The bidirectional reflectance $\rho$ modeled with the GEN model is then expressed as:

$$
\begin{aligned}
& \rho\left(\theta_{\mathrm{v}}, \theta_{\mathrm{s}}, \varphi\right)=\mathrm{a}(\lambda) \rho_{\mathrm{GEN}}\left(\theta_{\mathrm{v}}, \theta_{\mathrm{s}}, \varphi\right)+\mathrm{b}(\lambda) \\
& =\mathrm{a}(\lambda) \rho^{\operatorname{MRPV}}\left(\bar{\alpha}_{\mathrm{i}=1, \ldots 3}(\lambda), \theta_{\mathrm{v}}, \theta_{\mathrm{s}}, \varphi\right)+\mathrm{b}(\lambda)
\end{aligned}
$$

where $\mathrm{a}(\lambda)$ and $\mathrm{b}(\lambda)$ are the GEN model parameters.

Inverting the GEN model therefore consists of computing the linear regression coefficients (multiplying factor a and offset $b$ ) from the measured BRDF and the generic one.

\subsubsection{The Flexible Linear Kernel model (FLIK)}

A majority of BRDF models are made up of three kernels. Adding more kernels should increase the accuracy. The FLIK model is based on this idea, and we thus investigated the possibility of choosing the number of parameters (from 3 to 6). To determine the corresponding kernels, we used neural networks. This was performed in three steps:

(1) Simulation of a synthetic data set, using four models in four wave bands (green, red, near infrared and middle infrared): SAIL [18, 19], Hapke's model [9], MRPV, and 5 -scale [4]. $\mathrm{m}=427$ situations were thus simulated for $p=364$ combinations of view and solar angles. This can be resumed in a reflectance matrix $\left\lfloor\rho_{\mathrm{m}, \mathrm{p}}\right\rfloor$.

(2) Singular Value Decomposition [8] of the reflectance matrix: the reflectance matrix is decomposed into a product of three matrices:

$$
\left.\left.\left\lfloor\rho_{\mathrm{m}, \mathrm{p}}\right\rfloor=\left\lfloor\mathrm{U}_{\mathrm{m}, \mathrm{k}}\right\rfloor \Omega_{\mathrm{k}, \mathrm{k}}\right\rfloor \mathrm{V}_{\mathrm{k}, \mathrm{p}}\right\rfloor
$$

where, due to the reflectance matrix construction ( $\mathrm{m}$ situations $\times p$ angle combinations), $\left\lfloor U_{m, k}\right\rfloor$ depends only on the spectral band and canopy, $\left.\mid \Omega_{\mathrm{k}, \mathrm{k}}\right\rfloor$ is the singular value matrix that is diagonal and gives the variance explained by the kernel $\mathrm{k}$. The product $\left.\left\lfloor\mathrm{U}_{\mathrm{m}, \mathrm{k}}\right\rfloor \Omega_{\mathrm{k}, \mathrm{k}}\right\rfloor$ gives the FLIK parameters $\alpha_{i, i=1 \ldots k} \cdot\left[V_{k, p}\right\rfloor$ depends only on viewing and solar geometry and corresponds to the value of FLIK kernels for each of the 364 angle combinations. 
(3) Calibration of artificial neural networks (ANN) with the matrix $\left\lfloor\mathrm{V}_{\mathrm{k}, \mathrm{p}}\right\rfloor$ to get FLIK kernels. 4 back-propagation neural networks are considered, with two hidden layers ( 5 neurons, $\mathrm{k}$ neurons, $\mathrm{k}=3, \ldots, 6$ ). The learning rule is the Levenberg/Marquardt algorithm. ANN inputs are: $\cos \left(\theta_{\mathrm{s}}+\theta_{\mathrm{v}}\right), \cos \left(\theta_{\mathrm{s}}-\theta_{\mathrm{v}}\right), \cos \varphi$, that make FLIK reciprocal by construction. The singular values show that $90 \%$ of the variance is explained with the first three kernels (Tab. II).

Once the ANNs are calibrated, the kernel values are computed by using view and solar directions of reflectance measurements as inputs. The inversion process is performed as for any linear BRDF model.

\section{RESULTS AND DISCUSSION}

The 10 BRDF models were first tested in terms of accuracy to fit the reflectance data on the whole POLDER sampling. Then, we tested their extrapolation capacities by inverting them on a selected amount of data (perpendicular or principal plane) and running them in the forward direction to restore the whole sampling. Finally, we considered the model's performances as a function of the number of data available for the inversion. Performances were evaluated in terms of Root Mean Square Error (RMSE). As the solar angle value remained quite constant for each POLDER acquisition date (standard deviation less than $2^{\circ}$ ), we only investigated the extrapolation capacity for view angles. Results are shown as a function of the date of acquisition, the sampling, or the waveband, and are computed for the 37 considered crops.

\subsection{Accuracy of the fitting}

In this section, the models were inverted using the BRDF sampled in all directions. Table III shows the results obtained for the 10 models as a function of the wavebands, for all the 16 dates. RMSE are of the same order in the three visible bands, and higher in the near infrared, since the reflectance level at $865 \mathrm{~nm}$ increases. The Nadir model performed quite badly, with a RMSE of about twice the lowest value. This demonstrates the need for models that take into account the canopy reflectance anisotropy. The performances of the models from the literature were very similar, the MRPV model being slightly better. The FLIK model is also accurate, espe-

Table II. Cumulative percentage of variance explained by the FLIK kernels.

\begin{tabular}{lc}
\hline Kernel number & \% information \\
\hline 1 & 70.7 \\
2 & 82.4 \\
3 & 88.8 \\
4 & 93.5 \\
5 & 96.9 \\
6 & 100 \\
\hline
\end{tabular}

Table III. RMSE between measured and estimated directional reflectance, as a function of POLDER wavebands, for ten BRDF models. The inversion is performed on all sampling directions. The 16 dates are considered all together.

\begin{tabular}{lllll}
\hline Model & $443 \mathrm{~nm}$ & $550 \mathrm{~m}$ & $670 \mathrm{~nm}$ & $865 \mathrm{~nm}$ \\
\hline Nadir & 0.035 & 0.039 & 0.039 & 0.059 \\
Walthall & 0.016 & 0.018 & 0.017 & 0.028 \\
MRPV & 0.017 & 0.017 & 0.016 & 0.027 \\
Roujean & 0.018 & 0.019 & 0.018 & 0.028 \\
Li-Ross & 0.018 & 0.018 & 0.018 & 0.029 \\
GEN & 0.028 & 0.020 & 0.017 & 0.029 \\
FLIK3 & 0.018 & 0.018 & 0.018 & 0.028 \\
FLIK4 & 0.017 & 0.018 & 0.018 & 0.028 \\
FLIK5 & $\mathbf{0 . 0 1 5}$ & $\mathbf{0 . 0 1 6}$ & $\mathbf{0 . 0 1 6}$ & $\mathbf{0 . 0 2 5}$ \\
FLIK6 & $\mathbf{0 . 0 1 5}$ & $\mathbf{0 . 0 1 6}$ & $\mathbf{0 . 0 1 5}$ & $\mathbf{0 . 0 2 5}$ \\
\hline
\end{tabular}

cially when the number of parameters is higher than 4 since more than $95 \%$ of the BRDF can be described (Tab. II). The GEN model is not as good at short wavelengths where atmospheric effects are significant. As it is less flexible than the other models (only 2 parameters and a generic directional variation), it may be more sensitive to residual directional atmospheric effects.

Figure 2 shows the evolution of the RMSE as a function of the acquisition date for the Nadir, MRPV, FLIK6 and GEN when considering all the wavebands together. The same evolution is observed for all the models: the RMSE is maximum for the day of experiment 541. For this day, the POLDER images were contaminated by clouds. The evolution is therefore mainly due to the image quality. In the rest of the study, results are presented for the day of experiment 555 (July the 8th), for which a good image quality is observed. Only the $865 \mathrm{~nm}$ waveband is considered since the same behavior is observed for the other channels, with lower RMSE levels.

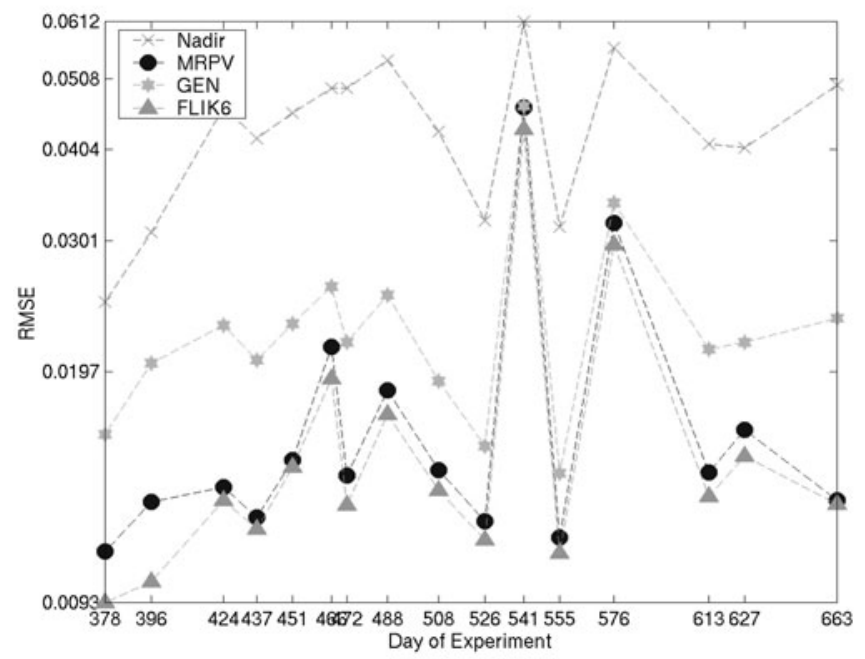

Figure 2. Evolution of the RMSE as a function of the acquisition date (logarithmic scale). Day of experiment is day of the year for year 1996 , and day of the year +366 for year 1997 . Wavebands are all considered together. 


\subsection{Extrapolation capacities}

In this section, for day 555 and the NIR band, two combinations of sampling inversion and sampling reconstruction are considered:

(1) Inversion near the principal plane sampling. Reconstruction on all sampling directions of the 5 flight lines.

(2) Inversion on the perpendicular plane sampling. Reconstruction on all sampling directions of the 5 flight lines.

Model inversion was performed if more than 6 bidirectional reflectance data were available. Considering the reconstruction in all sampling directions ((1) and (2)), the MRPV and GEN performed the best while the Nadir gave the highest RMSE (Fig. 3). The error is increased when the inversion was performed on the perpendicular plane. This is due to a low number of bidirectional reflectance data in this plane (on average, 9 data against 16 data near the principle plane). The more parameters you have when few data are used for the inversion, the better the fitting, but the extrapolation capacities are not so good. The increase of the RMSE may therefore become important for the FLIK models with more than 3 parameters. Although it does not take into account the hot spot feature, the Walthall model's performances near the principal plane are satisfactory since the hot spot peak was very rarely sampled during the ReSeDA campaign.

\subsection{Impact of the number of bidirectional data available for the inversion}

Figure 4 investigates the impact of the number of data available for the inversion of the two best models (the MRPV and GEN), and the Walthall and FLIK6 near the principal plane (reconstruction in all sampling directions). The 16 dates are taken into account to avoid particular situations. The results show that the number of sampling directions has an influence on the FLIK6 model, as it has been observed in Section 3.2. FLIK6 requires more than 12 directional data to get the same performances as the other models. The number of directions is, however, not the only limiting feature: the directions themselves as well as the state of the surface (bare soil, limited or high crop development) may also have an influence on the results: taking the MRPV model as an exam-
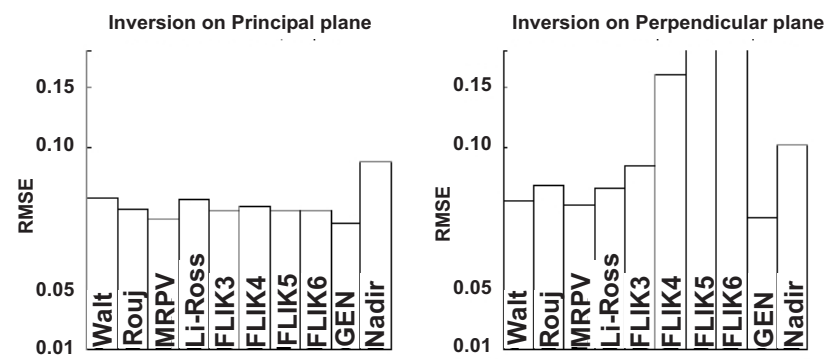

Figure 3. RMSE at $865 \mathrm{~nm}$ for day 555, as a function of models (logarithmic scale). The reconstruction is performed on all sampling directions.

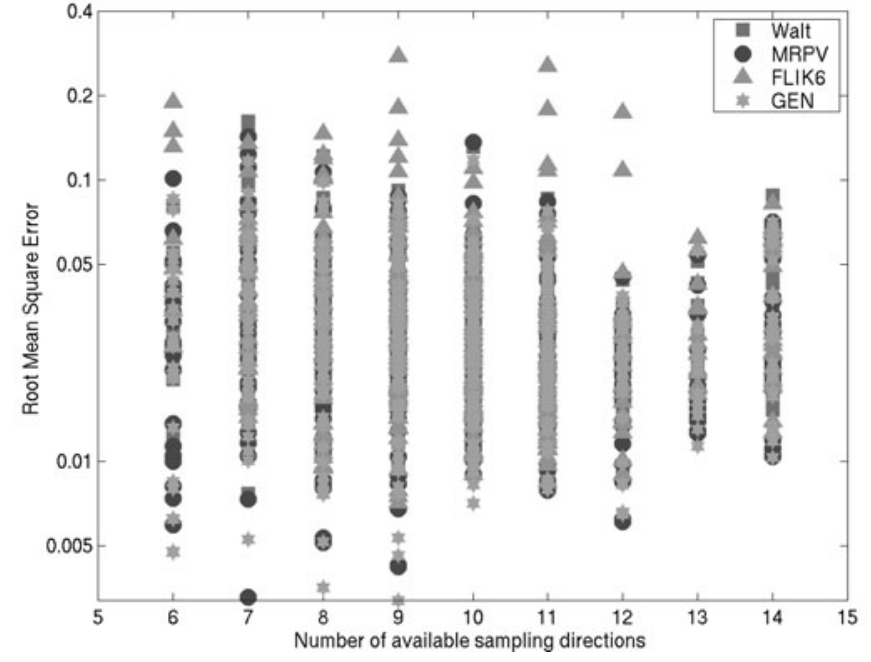

Figure 4. RMSE at $865 \mathrm{~nm}$ for day 555, as a function of number of sampling directions available.

ple, for some cases, higher RMSE are observed when inverting on 14 data instead of 6 .

\section{CONCLUSIONS}

This study is dedicated to the comparison of kernel-driven BRDF models using the experimental data set of the Alpilles/ReSeDA campaign. This data set was interesting since it corresponds to quite full bidirectional sampling of the reflectance as well as providing the BRDF of 37 fields ( 4 crop types) on 16 dates during the year. This allows the comparison of the models in terms of estimation accuracy as well as extrapolation capacities. The MRPV, and the generic model we developed performed slightly better than the others. Conversely, the results for the FLIK model with more than 4 parameters are not satisfactory when few data are available for the inversion. However, model's extrapolation capacities depend not only on the number of directional data used for the inversion, but also on the nature of the sampled directions or the type of the observed surface. In this study we were not able to investigate solar extrapolation capacities, since data were acquired at constant sun zenith angles. This has already been performed on a simulated data set by [22] who demonstrated that the Walthall model was not accurate as compared with the other models we studied. Further validations should be performed on experimental data sets. The use of the MRPV or GEN models to get normalized products from POLDER data is thus recommended. This could allow hemispherical reflectance estimates that are of great importance for characterizing the surface albedo [14, 22, 23].

Acknowledgements: The authors thank the CNES (Centre National d'Études Spatiales) for their financial support. 


\section{REFERENCES}

[1] Baret F., ReSeDA. Assimilation of multisensor and multitemporal remote sensing data to monitor soil and vegetation functioning, Final report. ENV4CT96032, 2000.

[2] Bicheron P., Leroy M., Bidirectional Reflectance Distribution Function signatures of major biomes observed from space, J. Geophys. Res. 105 (2000) 26669-26681.

[3] Boufies S., Bréon F.-M., A multi-year composite of GVI data as a clear reflectance database, Int. J. Remote Sens. 17 (1996) 1711-1726.

[4] Chen J.M., Leblanc S.G., A four-scale bidirectional reflectance model based on canopy architecture, IEEE Trans. Geosci. Remote Sens. 35 (1997) 1316-1337.

[5] Cihlar J., Manak D., D'Iorio M., Evaluation of compositing algorithms for AVHRR data over land, IEEE Trans. Geosci. Remote Sens. 32 (1994) 427-437.

[6] Engelsen O., Pinty B., Verstraete M., Martonchik J.V., Parametric bidirectional reflectance factor models: evaluation, improvements and applications, Ispra, Italy, 1996.

[7] Gitelson A.A., Kaufman Y.J., MODIS NDVI optimization to fit the AVHRR data series-spectral considerations, Remote Sens. Environ. 66 (1998) 34-35.

[8] Golub G.H., Loan C.V., Matrix Computations, Baltimore, 1996.

[9] Hapke B., Bidirectional reflectance spectroscopy. 1. Theory, J. Geophys. Res. 86 (1981) 3039-3054.

[10] Holben B.N., Characteristics of maximum value composite images from temporal AVHRR data, Int. J. Remote Sens. 7 (1986) 1417-1434.

[11] Kuusk A., The hot spot effect in plant canopy reflectance, in: Myneni R.B., Ross J. (Eds.), Photon-Vegetation interactions, Springer Verlag, 1991, pp. 139-159.

[12] Leroy M., Hautecœur O., Berthelot B., Gu X.F., The airborne POLDER data experiment, in: Baret F. (Ed.), EGS2000, INRA, Nice, France, 2001 .
[13] Leroy M., Roujean J.L., Sun and view angle corrections on reflectances derived from NOAA/AVHRR data, IEEE Trans. Geosci. Remote Sens. 32 (1994) 684-697.

[14] Privette J.L., Eck T.F., Deering D.W., Estimating spectral albedo and nadir reflectance through inversion of simple BRDF models with AVHRR/MODIS like data, J. Geophys. Res. 102 (1997) 29529-29542.

[15] Roujean J.L., Leroy M., Podaire A., Deschamps P.Y., Evidence of surface bidirectional effects from a NOAA/AVHRR multitemporal data set, Int. J. Remote Sens. 13 (1992) 685-698.

[16] Roujean J.L., Leroy M., Deschamps P.Y., A bidirectional reflectance model of the Earth's surface for the correction of remote sensing data, J. Geophys. Res. 97 (1992) 20455-20468.

[17] Taddei R., Maximum value interpolated MVI: a maximum value composite method improvement in vegetation index profiles analysis, Int. J. Remote Sens. 18 (1997) 2365-237.

[18] Verhoef W., Light scattering by leaf layers with application to canopy reflectance modeling: the SAIL Model, Remote Sens. Environ. 16 (1984) 125-141.

[19] Verhoef W., Earth observation modeling based on layer scattering matrices, Remote Sens. Environ. 17 (1985) 165-178.

[20] Walthall C.L., Norman J.M., Welles J.M., Campbell G., Blad B.L., Simple equation to approximate the bidirectional reflectance from vegetative canopies and bare soil surfaces, Appl. Opt. 24 (1985) 383-387.

[21] Wanner W., Li X., Strahler A.H., On the derivation of kernels for kernel-driven models of bidirectional reflectance, J. Geophys. Res. 100 (1995) 21077-21089.

[22] Wanner W., Strahler A.H., Hu B., Lewis P., Muler J.-P., Li X., BarkerSchaaf C.L., Barnsley M.J., Global retrieval of bidirectional reflectance and albedo over land from EOS MODIS and MISR data: theory and algorithm, J. Geophys. Res. 102 (1997) 17143-17161.

[23] Weiss M., Baret F., Leroy M., Bégué A., Hautecœur O., Santer R., Hemispherical reflectance and albedo estimates from the accumulation of across track sun synchroneous data, J. Geophys. Res. 104 (1999) 22221-22232. 